\title{
REFLEXIONES PARA UNA HISTORIA DE LA TEATRALIDAD RELIGIOSA POPULAR EN MÉXICO
}

\author{
BEATRIZ ARACIL VARÓN
}

\section{RESUMEN}

Las actuales manifestaciones del teatro religioso popular son fruto de un proceso de evolución, adaptación y transformación de formas dramáticas que fueron surgiendo, en muchos casos, a lo largo del período colonial. El presente artículo pretende centrarse en dicho proceso y, más concretamente, en los vínculos que cabría establecer entre formas contemporáneas de teatralidad (en especial del ámbito indígena) ligadas al calendario litúrgico cristiano y las del denominado «teatro evangelizador», impulsado por los misioneros españoles desde las primeras décadas de la conquista con el fin de instruir en la nueva fe a los naturales.

A partir de una revisión crítica de conceptos como «tradición», «discurso» o «documento», se intentarán trazar claves para la comprensión de una línea evolutiva que se nos revela discontinua, llena de modificaciones, rupturas, nuevas incorporaciones o recuperaciones de modelos teatrales, debidas a muy diversas causas históricas, sociales y culturales.

\section{REFLECTIONS FOR A HISTORY OF POPULAR RELIGIOUS HISTRIONICS IN MEXICO}

\section{ABSTRACT}

The present representations of popular religious theatre bave emerged from an evolutionary, adaptation and transformation process of dramatic forms which in many cases appeared during the colonial era. This article intends to concentrate on this process and, more concretely, on the possible links between contemporary dramatic forms (especially from indigenous backgrounds) linked to the Christian liturgical calendar and those from what is known as 'evangelist theatre' promoted by Spanish missionaries in the first decades following the conquest and aimed at teaching natives the new faith.

Keys to understanding an evolutionary path will be plotted via a critical revision of concepts such as 'tradition', 'discourse' or 'document', revealing a discontinuity full of changes, ruptures, new additions to or recoveries of theatre models due to extremely diverse historical, social and cultural reasons.

\section{INTRODUCCIÓN}

En el prefacio a su libro El teatro popular en Hispanoamérica. Una bibliografía anotada
(1979), René Acuña definía el «teatro popular»o «teatro folklórico» como «un conjunto de piezas dramáticas (...) por lo común anónimas, que se conservan por tradición oral o

\section{Beatriz Aracil Varón}

Doctora en Filología Hispánica por la Universidad de Alicante (España). Especialista en teatro hispanoamericano colonial, se ha dedicado asimismo en los últimos años a la recuperación de la Crónica de Indias en la novela y el teatro latinoamericanos del siglo XX. Entre sus publicaciones cabe destacar El teatro evangelizador. Sociedad, cultura e ideología en la Nueva España del siglo XVI (Roma, Bulzoni, 1999), Abel Posse: de la crónica al mito de América (Universidad de Alicante, 2004) y la coedición del libro Fiesta y teatralidad de la pastorela mexicana (UNAM, 2004), así como numerosos artículos que forman parte de obras colectivas editadas en España, Francia y México. Actualmente es profesora de Literatura Hispanoamericana en la Universidad de Alicante y Responsable Académica del área de América Latina en la Biblioteca Virtual Miguel de Cervantes.
Reflexiones para una historia de la teatralidad religiosa popular en México

BEATRIZ ARACIL VARÓN 


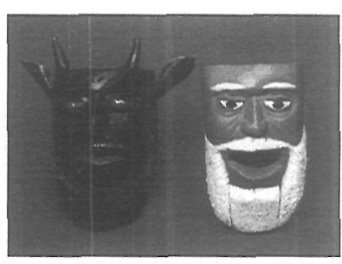

Máscaras para una danza de moros y cristianos. Morelos.

1

René Acuña, El teatro popular en Hispanoamérica. Una bibliografía anotada, México, UNAM, 1979, pág. 9.

2

Id.

3

Ibidem, pág. 10.

4

Cf., entre otros, A treasure of Mexican Folkways, New York, Crown Publishers, 1947

5

Entre los que cabría citar Folklore de San Pedro Piedra Gorda Zacartecas (junto a Virginia R.R. de Mendoza, México, Instituto Nacional de Bellas Artes, 1952

y Folklore de la región central de Puebla (México, Centro Nacional de Investigación, Documentación e Información Musical Carlos Chávez, 1991) o sus ediciones de «La Danza de la Conquista» (Anuario de la Sociedad Folklórica de México, 1944, vol. IV, págs. 155-186); "Drama de la Pasión como se representa en Milpa Alta D.F. Manuscrito de Adalberto Fuentes Cruz») (Anuario de la Sociedad Folklórica de México 1949, vol. VI, págs. 249-371); Una Adoración de Pastores en Chilpancingo (México, UNAM 1950): "Drama tradicional. Mo risma de Zacalecas que se representa el 24 de junio» (Anuario de la Sociedad Folklórica de México, 1954, vol. VIII, págs. 141-162).

6

Para un recorrido por la obra de este autor puede consultarse la «Reseña bibliográfica de Fernando Horcasitas» en Fernando Horcasitas, Teatro náhuatl II, coord. por María Sten y Germán Viveros, México, UNAM, 2004, págs. 429-4.37.

7

Arturo Warman, La danza de moros y cristianos, México, SEPSetentas, 1972

8

Juan Villegas, Historia multicultural del teatro y las teatralidades

Reflexiones para una historia de la teatralidad religiosa popular en México

BEATRIZ ARACIL VARÓN

escrita, y que se suelen representar ocasional o periódicamente» ${ }^{1}$, y planteaba, entre otras cuestiones, dos problemas importantes para su estudio: en primer lugar, "su existencia marginal a los documentos históricos y civiles» ${ }^{2} y$, en segundo lugar, la constatación de que, a fines de los 70, el teatro popular no había encontrado aún «la puerta por la cual ingresar al recinto universitario» ${ }^{3}$.

Aunque volveré inmediatamente a la definición propuesta por Acuña para confrontarla a otras acepciones de lo «popular» aplicadas al teatro, lo que me interesa destacar ahora es la utilización en la misma del término «tradición», que lleva a su vez al autor a partir de las «raíces peninsulares y autóctonas» de estas manifestaciones dramáticas: el tipo de teatro popular al que se refiere el investigador guatemalteco es fruto de la apropiación ( $y$, por tanto, de una sucesiva variación) de formas dramáticas a lo largo incluso de siglos, y cualquier acercamiento al mismo hace necesarios, por tanto, una búsqueda de las «raíces» y un estudio de su desarrollo.

El investigador que intente trazar el recorrido histórico por estas formas tradicionales de teatralidad hallará en la actualidad prácticamente los mismos problemas planteados por Acuña hace casi tres décadas: el carácter marginal de dichas manifestaciones dramáticas (que le llevará a enfrentarse con la problemática del documento) y la escasez de estudios críticos sobre las mismas, no sólo desde la perspectiva del folklore (hacia la que apuntaba Acuña) sino también, y quizá de forma más acusada, desde la historiografía teatral: por lo que respecta en concreto al ámbito mexicano, contamos con interesantes trabajos realizados por folkloristas como Frances Toor ${ }^{4}$ y Vicente T. Mendoza ${ }^{5}$ o etnógrafos como Fernando Horcasitas ${ }^{6}$, y con la existencia de algún valioso estudio de conjunto como el de Warman sobre la danza de moros y cristianos ${ }^{7}$, en el que se aúnan las perspectivas histórica y antropológica, pero en general todavía resulta difícil encontrar

en América Latina, Buenos Aires, Galerna, 2005, pág. 24.

9

Fernando Horcasitas, El teatro náhuatt, México, UNAM, 1974, pág. 163-164.

10

Esta tesis fue ya defendida, entre otros, por José Juan Arrom, este tipo de actividad teatral como objeto de los estudios historiográficos, que la excluyen precisamente por su carácter marginal. Como explicaba recientemente Juan Villegas,

El discurso crítico, no consciente de sus propios fundamentos ideológicos ni de su dependencia cultural, ha producido una historia parcial, en la cual se han privilegiado textos estéticamente europeizantes e ideológicamente convenientes a los sectores sociales en el poder. Al mismo tiempo, ha dejado fuera enormes espacios de producción de textos teatrales que han sido automáticamente discriminados y marginados ${ }^{8}$.

Ahora bien, la constatación de estas limitaciones o lagunas en la investigación teatral puede (y debe) ser también un acicate para la imprescindible incorporación de las actuales manifestaciones del teatro religioso popular a una historia del teatro (en nuestro caso, del teatro mexicano) no sólo por su importancia como producto cultural y testimonio privilegiado de los grupos sociales que las generan sino también por el hecho de constituirse como documentos que nos informan sobre la actividad teatral de épocas anteriores en la medida en que son fruto de un proceso de evolución, adaptación y transformación de formas de teatralidad que se remontan, en algunos casos, al período precolombino o al colonial.

Mi objetivo en el presente artículo es centrarme en dicho proceso evolutivo, y, más concretamente, en los vínculos que cabría establecer entre ciertas formas contemporáneas de teatralidad en el ámbito indígena y las de ese primer teatro propiamente mexicano, sincrético, que fue el impulsado por los misioneros españoles para la evangelización de los naturales desde las primeras décadas de la conquista.

He señalado ya en algún trabajo previo que, frente a la postura defendida por Fernando Horcasitas, para quien, a excepción del ciclo de la Pasión, las pastorelas y el ciclo de Santiagos, Moros y Cristianos y Pilatos, «no existe el menor vestigio del teatro misionero entre los indígenas modernos» ${ }^{9}$, en mi opinión son precisamente esas «excepciones», tan destacadas en el contexto de la fiesta popular mexicana, las que permitirían hablar de cierta continuidad (entendida en cualquier caso como un complejo y discontinuo proceso) del teatro evangelizador entre la población indígena hasta la actualidad» ${ }^{10}$.

Serán por ello, sobre todo, esas formas de teatralidad (con sus rasgos peculiares de evolución) las que me servirán de base para 
algunas reflexiones sobre las características, las etapas y los parámetros de análisis de esas líneas de continuidad; reflexiones que parten necesariamente a su vez de una revisión de conceptos básicos ya citados (lo popular, lo tradicional, lo indígena, discurso marginal, documento...) que continúan siendo aprovechados y replanteados desde diversas disciplinas y perspectivas críticas.

\section{UNA CUESTIÓN DE CONCEPTOS}

En los años en que René Acuña definía el «teatro popular» a partir de la idea de tradición y como sinónimo de «teatro folklórico», el director brasileño Augusto Boal escribía diversos trabajos en los que, desde un planteamiento marxista basado en la dicotomía opresor/oprimido, advertía que, "para ser popular, el teatro debe abordar siempre los temas según la perspectiva del pueblo, vale decir, de la transformación permanente, de la desalienación, de la lucha contra la explotación, etc.» ${ }^{11}$, y establecía diversas categorías y técnicas de creación de un teatro popular entre las que citaba el aprovechamiento, con los fines citados, de las fiestas $\mathrm{y}$ tradiciones populares ${ }^{12}$.

La propuesta de Boal resulta representativa de una línea ampliamente difundida en la práctica y en la crítica teatral latinoamericana de las últimas décadas que Donald Frischmann ha explicado del siguiente modo:

...el término [«teatro popular»] ha llegado a significar algo más que un teatro folklórico de autor anónimo perpetuado a través de la tradición escrita u oral, tal cual lo entienden Englekirk y Acuña. Hoy día, dentro del panorama del nuevo arte popular latinoamericano, como resultado de nuevas condiciones económicas, sociales y culturales (...), el término evoca antes que nada la idea de un teatro no comercial, creado por y para las clases populares, un teatro de recursos materiales limitados, y cuyo propósito de promover los valores culturales populares generalmente se complementa con otros de tipo político y social ${ }^{13}$.

A pesar de los problemas metodológicos que plantea una definición ideológica de lo «popular» aplicada a la actividad teatral, acrecentados por la ambigüedad del propio término «popular» ${ }^{14}$, lo cierto es que cualquier acercamiento actual al «teatro popular» deberá tener presente, como propone Frischmann, la doble vertiente del término, esto es, la existencia de «un teatro popular tradicional y folklórico de raíces indígenas y europeas y de tipo histórico y religioso» que «sigue vivo hoy día aunque en grado cada vez más mermado» y el surgimiento en América Latina, y concretamente en México, de un «nuevo teatro popular» (ampliamente estudiado por el investigador estadounidense) que «existe de, por y para las clases populares», aunque «incorpora elementos del teatro popular tradicional, reinterpretándolos de acuerdo con la situación vital del pueblo»15.

Debido a esta ambivalencia del término, resulta necesaria una delimitación del primer tipo de teatro señalado por Frischmann (que es el que nos ocupa) respecto de las nuevas formas de teatro popular que han surgido en México. Y parece claro que, aun cuestionando la validez de una definición como la de Acuña, dicha delimitación deberá incorporar como conceptos esenciales los de «tradición» $\mathrm{y}$ «folklore», o al menos asumir parcialmente la reflexión teórica que en torno a ambos conceptos (y más allá de su aplicación al teatro) se ha venido desarrollando durante décadas desde diversas disciplinas, una reflexión que será de gran ayuda a la hora de analizar tanto la realidad actual como la evolución de las formas de teatralidad vinculadas al calendario festivo.

El origen de la palabra «folklore» está vinculado a lo popular y lo tradicional: su inventor, el inglés William J. Thoms, formó el término a partir de las voces folk (pueblo) y lore (saber, conocimiento) y afirmó que «el Folklore estudiaría únicamente el saber tradicional de las clases populares»16. Ya en la década de los sesenta, e intentando superar los conflictos teóricos entre folkloristas y etnógrafos, el peruano José María Arguedas definía el folklore como "el arte del pueblo» y el Folklore como la ciencia que «estudia, de modo general, las artes tradicionales de cualquier pueblo $\gg^{17}$. Por su parte, Efraín Morote, en los ochenta, al definir el Folklore como «un sector específico de las Ciencias Histórico-Sociales que busca determinar las leyes del surgimiento, desarrollo y extinción de las tradiciones populares», añadía que esta definición «demanda, cuando menos, una explicación nítida del criterio con que se manejan dos categorías capitales y concurrentes: Tradiciones y Populares ${ }^{18}$. Más recientemente, Mildred Merino señalaba como dos de los elementos esenciales del hecho folklórico su carácter popular o colectivo y su cualidad tradicional o generacional (su transmisión oral de padres a hijos). Merino, en cualquier caso,
11

Augusto Boal, Técnicas latinoamericanas de teatro popular: una revolución copernicana al revés, Buenos Aires, Corregidor, 1975, pág. 28

12

Véase ibidem, págs. 82-92.

13

Donald Frischmann, El nuevo teatro popular en México, México, INBA, 1990, póg, 28.

14

Cf. Juan Villegas, Para un modelo de historia del teatro, Irvine (California), Gestos, 1997, págs. 169-172.

15 Frischmann, op. cit., pág. 42

16

José María Arguedas, «Qué es el Folklore» [1964], en Mildred Merino de Zela (comp.), Ensayos sobre folklore peruano, Lima, Universidad Ricardo Palma, 1999, pó́g. 39

17

Arguedas en ibidem, pág. 42. Nótese, sin embargo, la marginalidad del teatro en este tipo de trabajos, tal como denunciaba Acuña, ya que Arguedas continúa delimitando el ámbito de estudio del Folklore a «muy particularmente sus cuentos, leyendas, danzas y canciones» (id.).

18

Efraín Morote, "Sobre el folklore» [1985], en ibidem, pág. 67 (cf. sobre ambos conceptos págs. 67-71)

Reflexiones para una historia de la teatralidad religiosa popular en México

BEATRIZ ARACIL VARON 
Véase Mildred Merino, «Prólogo» a ibidem, págs. 16-21.

20

Ramón Menéndez Pidal, Romancero hispánico (hispano-portugués, americano y sefardi), Madrid, Espasa-Calpe, 1968, tomo I, pág. XV.

21

Ibidem, p. 45

22

Ibidem, p. 46

23

Recordemos las propias dificultades de los folkloristas para delimitar no sólo su objeto de estudio sino sobre todo su aparato teórico-metodológico, sobre el cual advertía Morote: «no podemos por menos que reconocer que el ingente trabajo realizado hasta hoy en la esfera del FoIklore, con todo lo plausible que pueda parecernos, ha contribuido poco, casi nada, al establecimiento de Conceptuaciones Básicas relativas a la esencia de la propia disciplina» (Morote en Merino, op. cit., pág. 64).

24

Paulo de Carvalho-Neto, "Concepto y realidad del teatro folklórico latinoamericano", Folklore Americano (México), 1977, núm. 23 (junio), págs. 101-102.

25

Domingo Adame, Teatros y teatralidades en México. Siglo XX Xalapa, Universidad Veracruzana, 2004, págs. 105-106.

26

Véase Carvalho, op. cit., págs. 102-103.

\section{7}

Véase Merino, op. cit., págs. 21-22.

\section{8}

Warman, op. cit., págs. 62-63.

Reflexiones para una historia de la teatralidad religiosa popular en México

BEATRIZ ARACIL VARÓN matizaba el sentido de estos dos elementos aclarando, en primer lugar, que, dadas las distintas acepciones del término "popular», no todo lo popular es folklórico, pero «todo lo folklórico sí es popular»y, en segundo lugar, haciendo derivar de lo tradicional a su vez otros rasgos como la plasticidad (ductilidad, asimilación que permite variaciones sin transformación de lo esencial) y el anonimato (por convertirse en creación colectiva) ${ }^{19}$.

En realidad, la utilización, por parte de $\mathrm{Me}$ rino, de los conceptos «popular» y «tradicional» no difiere demasiado de la formulada por Ramón Menéndez Pidal hace varias décadas en sus estudios sobre el Romancero español e hispanoamericano. Recordemos que Menéndez Pidal proponía entonces sustituir «el nombre tan arraigado de poesía popular (...) por el concepto y el nombre más científico de poesía tradicional ${ }^{20}$. Su explicación, perfectamente aplicable al teatro, se basaba en el hecho de que lo tradicional implica un grado superior a lo popular en la medida en que no sólo supone «aceptación» sino también "asimilación», esto es, "la acción continuada e ininterrumpida de las variantes» ${ }^{21}$. Para el erudito español,

Entre una y otra categoría hay, pues, una diferencia cuantitativa, porque la tradición supone una popularidad continua, prolongada y más extensa; pero hay también una diferencia cualitativa, pues la obra tradicional, al ser asimilada por el pueblo-nación, es reelaborada en su transmisión y adquiere por ello un estilo propio de la tradicionalidad; no es sólo anóni$\mathrm{ma}$, sino que es impersonal ${ }^{22}$.

Asumiendo los presupuestos de Menéndez Pidal, un teatro tradicional se definiría como el que es considerado patrimonio común, con amplia difusión durante largo tiempo en la comunidad, que, debido a su asimilación por ésta, es «impersonalizado» y continuamente transformado, ajustado a los sucesivos contextos culturales. La pertinencia del término «teatro tradicional» vendría dada entonces tanto por la implicación de los rasgos señalados como por su unicidad de sentido, frente a la plurisignificación del concepto «teatro popular» (en el que, como ya se ha señalado, se aúnan la ambigüedad del propio adjetivo «popular» y su ambivalencia en el ámbito de la investigación teatral) o incluso del de «teatro folklórico», respecto al que también encontramos una diversidad de interpretaciones críticas" ${ }^{23}$; cito a este propósito sólo dos ejemplos: mientras Paulo de Carvalho-Neto definía el teatro folklórico como ...un teatro de raíces profundas en el tiempo (antigüedad) y en el individuo (inconsciencia), transmitiéndose sin enseñanzas organizadas (no-institucionalización), respondiendo a necesidades psicológicas (funcionalismo) del hombre de todas partes del globo (universalismo) $)^{24}$;

para Domingo Adame, en cambio, se trata de un teatro que

...toma elementos culturales populares, indígenas o mestizos, rurales o urbanos, insertándolos en un contexto cultural distinto al que surgen, dando por resultado un producto híbrido distanciado de sus fuentes, sus realizadores y sus receptores; es decir, un objeto para el consumo espectacular o la propagación de una visión de lo «autóctono» 25 .

Parece, pues, adecuado aceptar como concepto predominante el de «teatro tradicional», lo cual no invalida, como ya se ha apuntado, el aprovechamiento de reflexiones teóricas en torno al folklore y al teatro folklórico. En este sentido, y acudiendo a los autores ya citados, es oportuno recordar al menos dos aspectos señalados por Carvalho esenciales para comprender la evolución de este tipo de manifestaciones teatrales: su inserción en el marco más amplio de la fiesta y la «desaparición constante y progresiva de la 'palabra'» en las mismas a lo largo del tiempo ${ }^{26}$. De igual modo, resulta interesante volver a la caracterización realizada por Merino para apuntar otro rasgo básico del hecho folklórico, el de su funcionalidad: la vigencia de cualquier fenómeno folklórico ( $y$, por tanto, también del teatro) está en estrecha vinculación con la manera en que sirve y refleja «los intereses, ideales, hábitos y costumbres» de una comunidad ${ }^{27}$. Como explica Warman respecto a la danza dramática de moros y cristianos, si una representación folklórica pervive (en el caso de las morismas «desde sus orígenes medievales hasta la actualidad»), «debe eso a su función (...), a la capacidad de satisfacer una necesidad cultural vigente $»^{28}$.

La funcionalidad del teatro tradicional es mayor en las zonas rurales: su aislamiento, su mermado desarrollo económico, su carácter conservador, suelen hacer de ellas espacios favorables a la pervivencia de costumbres ancestrales que refuerzan los rasgos identitarios de la comunidad y la participación de sus individuos. El propio Menéndez Pidal insistía en que la difusión extensa de la tradición (concretamente del canto tradicional) se debía a que había llegado «a arraigar en las clases 
rurales, las menos propensas a los cambios de la moda» ${ }^{29}$. En México, esas comunidades rurales vienen a identificarse, en general, con los grupos indígenas, lo que nos sitúa ante un nuevo concepto de difícil definición porque, como explica Warman, en la actualidad, el término indígena «no implica en ningún caso prehispánico, ni una lengua, ni un traje o una clasificación étnica» sino que

...es un nombre para reconocer un tipo de sociedad y cultura. La historia nos hace referir ese término a grupos que llevaron el mismo nombre en épocas pasadas, y a partir de que dos culturas diferenciadas se enfrentaron y se reconocieron como extraños ${ }^{30}$.

Partiendo de parámetros sociales y culturales (y no étnicos o lingüísticos), podremos considerar que es su conciencia diferencial respecto a la cultura dominante la que permite definir como «indígenas» a estos grupos que sustentan todavía, en el medio rural en el que viven (o en la traslación de éste al ámbito urbano: el barrio), tradiciones creadas por y para los indígenas del período colonial. No es sólo, pues, el carácter rural (como en otros lugares) sino también, y de manera especial, la conciencia de la diferencia, de la marginalidad, el rasgo esencial de estas culturas en las que encontramos formas tradicionales de teatralidad, tal como recuerda Ariza Acevedo en su estudio sobre la pervivencia de un teatro evangelizador colonial en Chilapa (Guerrero):

Hoy en día, todas las piezas de teatro que se encuentran en la región, son conservadas gracias a los campesinos (...). Y la razón de la subsistencia del teatro evangelizante en esta región no es otra sino el olvido y el atraso en que se encuentran en estas regiones marginadas (...). Es como si los campesinos que las conservan siguieran viviendo como hace cuatrocientos años ${ }^{31}$.

Ahora bien, esta última consideración permitiría a su vez observar el teatro religioso tradicional de las comunidades indígenas como un «discurso teatral marginal», tal como este concepto ha sido definido por Juan Villegas. En efecto, entendiendo el teatro como un tipo de discurso ${ }^{32}$, Villegas propone distinguir discursos teatrales "producidos por los sectores culturalmente hegemónicos, aunque su destinatario puede pertenecer a sectores de otros grupos culturales» ${ }^{33}$, y discursos teatrales marginales, esto es, «manifestaciones teatrales que no coinciden con los códigos estéticos e ideológicos de los emisores del discurso crítico hegemónico» ${ }^{34}$; advierte además que, por muy diversos motivos, un discurso teatral hegemónico puede acabar siendo marginal (de hecho, «la historia del teatro no es sino, precisamente, la historia de discursos desplazados desde su posición de hegemonía»35) o convirtiéndose en un discurso subyugado, es decir, prohibido o censurado por el sistema en el poder.

Las categorías establecidas por Villegas (discurso hegemónico, marginal, desplazado y subyugado), sin pretender ser fijas o exclusivas, dan cuenta de la pluralidad de los discursos teatrales a partir de su historicidad y de su contexto de producción, resultando especialmente útiles en su aplicación al teatro religioso tradicional mexicano, en primer lugar, porque nos recuerdan la pertinencia de recuperar este tipo de discurso marginal como parte de la historia del teatro: como explica Villegas, «historizar» significa, entre otras cosas, «investigar tanto los discursos teatrales dominantes como los marginales o subordinados, conceder importancia a los marginados y explicar las causas estéticas y sociales de su marginación» ${ }^{36}$. En segundo lugar, y en estrecha relación con lo anterior, esta categorización puede servir para explicar el proceso de evolución del teatro evangelizador colonial hacia las formas actuales de teatro tradicional como configuración de un «discurso desplazado» (de la hegemonía a la marginalidad o incluso la subyugación): si, para el propio Villegas, «el teatro de los franciscanos constituía en ese momento histórico el discurso teatral hegemónico dirigido a un sector social [y] culturalmente marginal» ${ }^{37}$, esas mismas manifestaciones teatrales, en manos ya de las comunidades indígenas, se fueron «desplazando», convirtiéndose en discursos teatrales marginales (llegando a ser prohibidas en ocasiones, al menos durante el período colonial, por mostrar una apropiación heterodoxa de la religión cristiana).

Paradójicamente, este carácter marginal, como señalaba Ariza Acevedo, debió favorecer en buena medida la pervivencia de manifestaciones teatrales, pero también ha dificultado la conservación de documentos sobre su existencia. En cualquier caso, ésta es sólo una de las vertientes de la problemática que nos plantean los documentos con los que trabajamos, una problemática que se inicia con la delimitación misma de lo que entendemos por «documento» y de los parámetros básicos que deberá tener en cuenta el investigador en el manejo del mismo.
29

Menéndez Pidal, op. cit., pág. 45.

30

Warman, op. cit., pág. 165.

31

Maclovio Ariza Acevedo, El teatro de evangelización en Chilapa, Guerrero, Chilpancingo, Universidad Autónoma de Guerrero, 1990, pág. 33.

32

Es decir, "como un acto de comunicación entre un emisor y un destinatario (receptor) en una situación específica, en el cual el emisor utiliza una pluralidad de signos (...) para construir un imaginario social y comunicar un mensaje a sus receptores》 (Villegas, Historia multicultural..., op. cit., pág. 15).

33

Ibidem, pág. 24.

34.

Ibidem, pág. 25.

35

Villegas, Para un modelo..., op. cit., pág. 128.

36

Ibidem, pág. 59.

37

Ibidem, pág. 159.

\begin{tabular}{c}
$\begin{array}{c}\text { Reflexiones para una historia } \\
\text { de la teatralidad religiosa popular } \\
\text { en México }\end{array}$ \\
\hline BEATRIZ ARACIL VARÓN
\end{tabular} 


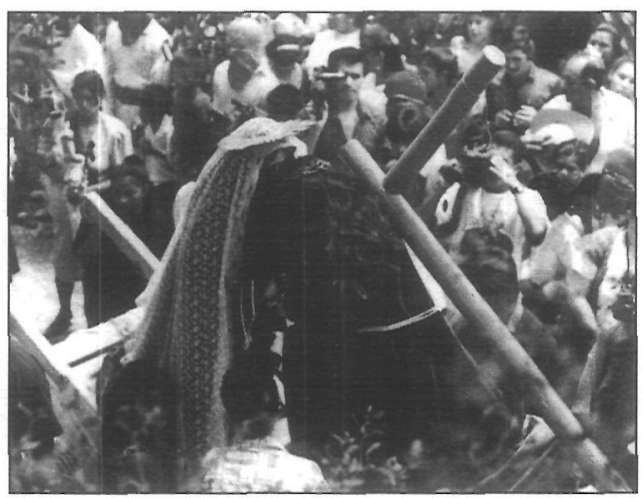

Pasión de Tzintzuntzan (Michoacán). 1995. Foto de Oscar Armando García.

38

Véase Marco De Marinis, Com prender el teatro: lineamientos de una nueva teatrología, Buenos Aires, Galerna, 1997, págs. 38-53.

39

Ibidem, pág. 45.

40

Ibidem, pág. 38.

41

Villegas, Para un modelo..., op. cit., pág. 51.

\section{2}

Los fastos eran espectáculos celebrativos con los que la ciudad agasajaba a sus reyes; en ellos se llevaban a cabo torneos, justas, juegos de juglares $y_{1}$ como un elemento muy destacado, enfrentamientos entre moros $y$ cristianos que evocaban los episodios de la cruzada contra el Moro, en especial a través de la toma de un castillo o de batallas de galeras (cf. Joan Oleza, «Las transformaciones del fasto medieval», en Teatro y espectáculo en la Edad Media, Instituto de Cultura Juan Gil-Albert, Diputación de Alicante y Ajuntament d’Elx, 1992, págs. 47-51).

\section{3}

Sobre las implicaciones político religiosas de este tipo de representaciones en el México del XVI, véase Beatriz Aracil, El teatro evangelizador. Sociedad, cultura e ideologia en la Nueva España del siglo XVI, Roma, Bulzoni, 1999, págs. 449-519.

Reflexiones para una historia de la teatralidad religiosa popular en México

BEATRIZ ARACIL VARÓN
Para abordar este último concepto, me parece pertinente acudir a los planteamientos de Marco De Marinis $^{38}$, quien, buscando la confluencia entre la semiótica y la historiografía teatral, define el documento como un objeto de cultura construido en cuanto tal por el historiador y nos advierte sobre algunos aspectos esenciales del mismo y su tratamiento, entre los que cabría destacar los siguientes: en primer lugar, que el documento suele consignar lo excepcional (lo cual nos obligará a tener mucho cuidado de tomar como norma la excepción); en segundo lugar, que ni la presencia ni la ausencia de un documento es casual, como tampoco lo son las lagunas, los silencios de éste; $y$, en tercer lugar, que el historiador es quien rescata e interpreta el documento: éste nunca habla por sí sólo, es una pura potencialidad que adquiere su sentido en la medida en que es interpretado por el investigador; en dicha interpretación será fundamental «leer los documentos relacionándolos con otros documentos, iluminándolos y completándolos recíprocamente» ${ }^{39}$ y que esta relación, además, pueda realizarse entre documentos directos (teatrales) e indirectos (externos, pero evidenciadores de una cultura).

Siguiendo las directrices señaladas, el investigador que estudie la evolución de la teatralidad religiosa tradicional deberá indagar, por ejemplo, los motivos por los que en determinados períodos encontramos un vacío en los documentos, tomar en consideración las posibles motivaciones no religiosas de un documento inquisitorial sobre una determinada representación o buscar las razones por las que determinado cronista quiso consignar cierto hecho teatral; del mismo modo, deberá acudir de forma imprescindible a las fuentes primarias «indirectas» que nos informen sobre otras manifestaciones artísticas o sobre la religiosidad de los grupos indígenas en distintas épocas, pero también sobre la realidad política, social, cultural mexicana de cada período: dichos documentos permitirán lo que De Marinis considera un «análisis contextual de los hechos teatrales» ${ }^{40}$ o, como diría Villegas, «historizar» en el sentido de «establecer la contextualidad del discurso teatral. Es decir, la producción del significado dentro del contexto social y político de la época en que fue producido o representado ${ }^{41}$.
APUNTES PARA EL ESTUDIO DE LA TEATRALIDAD RELIGIOSA TRADICIONAL DESDE UNA PERSPECTIVA HISTORIOGRÁFICA

Como he indicado al inicio de estas páginas, la propuesta de trabajo que esbozo en ellas es la de trazar líneas de evolución desde las formas teatrales implantadas por los misioneros en el territorio mexicano durante el primer siglo de la colonia hasta determinadas manifestaciones de teatralidad religiosa en las actuales comunidades indígenas. Parto de la hipótesis de que es posible establecer tales líneas de evolución a pesar de que éstas se nos puedan revelar discontinuas, llenas de modificaciones, rupturas, nuevas incorporaciones o recuperaciones de modelos teatrales, y propongo precisamente una profundización en esa problemática frente a las dos posturas más comunes en torno a la posible vinculación entre el teatro evangelizador y el teatro religioso tradicional actual: el rechazo de la misma por parte de estudiosos destacados de este teatro (comenzando por el propio Horcasitas) y el hecho de haberse constituido como lugar común de trabajos sobre determinadas manifestaciones teatrales hasta el punto de convertirse en afirmación hueca, no fundamentada, en torno a los orígenes remotos de estas representaciones. Ahondar en las formas y motivaciones de este proceso evolutivo resulta absolutamente necesario para la configuración en México de esa historia del teatro plural y contextualizada que propone Villegas y a la que están contribuyendo numerosos investigadores actuales.

En la determinación de esas líneas de continuidad, podríamos distinguir tres temáticas básicas que hunden sus raíces en el teatro europeo medieval, tal como éste fue trasladado a la Nueva España por los misioneros españoles: las referentes a la Navidad y la Pasión (los dos festejos fundamentales del calendario litúrgico cristiano) y la tradición de «moros y cristianos» (en sus distintas variantes), que tiene sus orígenes en los fastos cortesanos medievales ${ }^{42}$ y que fue incorporada al contexto mexicano tanto por los conquistadores (como parte de la «cultura de conquista») como por los frailes, quienes la difundieron entre la población indígena como un eficaz medio de evangelización (al tiempo que de justificación de la conquista militar y de incorporación de los naturales al Imperio español $)^{43}$.

Mientras la pertenencia concreta al ciclo litúrgico fijó las fechas de las representaciones de Navidad (la adoración de los Reyes el día 
de la Epifanía y, sobre todo, la adoración de los pastores en Nochebuena, que derivaría hacia la actual pastorela) y de Semana Santa (con la escenificación de la Pasión de Cristo), los festejos de «moros y cristianos», tanto en España como en México y otras zonas de América, se desarrollaron en el ámbito popular como parte de la celebración de las fiestas en honor a la Virgen y los santos patronos, tanto si éstos se relacionaban de algún modo con la idea de conquista (Santiago, San Miguel...) como si no. En México además, durante el período colonial, los santos (a menudo evocadores de algún dios prehispánico) se convirtieron en «el símbolo principal que identificaba y unificaba a cada entidad sociopolítica [indígena] $\gg^{44}$, de manera que, como explica Lockhart, "el día que se celebraba el santo patrono de la unidad era la ocasión más importante del año para toda la población (...); en dicha celebración participaban todos y en ella se mostraba la fuerza y organización interna de la entidad» ${ }^{45}$. La incorporación de las danzas de moros y cristianos a esta fiesta principal demuestra el arraigo que este tipo de representaciones adquirió en las comunidades indígenas, arraigo vinculado a su vez, entre otros aspectos, a esa demostración identitaria que era, y continúa siendo, la fiesta del santo patrono.

Aunque continúen desarrollándose en ese mismo marco festivo, es evidente que las representaciones que tienen lugar hoy día han sufrido necesariamente un proceso evolutivo (recordemos que no existe tradicionalidad sin apropiación y, por tanto, transformación) que hace difícil reconocer sus posibles raíces coloniales. $\mathrm{Y}$, sin embargo, muy a menudo dichas raíces existen a incluso explican el sentido último de algunas escenificaciones actuales. Veamos a grandes rasgos qué información aportan las fuentes conocidas hasta ahora sobre cada una de las líneas temáticas señaladas:

En el caso de las piezas sobre la Pasión, la necesaria fidelidad a unos Evangelios que describen con detalle estos hechos de la vida de Jesús hace muy complicado situar el momento de elaboración del texto dramático y su posible reelaboración en el tiempo ${ }^{46}$. Lo cierto es que, contra la opinión de aquellos investigadores para los que el sacrificio de Cristo no debió ser un tema conveniente en las primeras décadas de la evangelización (por su posible evocación de ritos prehispánicos $)^{47}$, las crónicas registran la puesta en escena habitual de este tema de conocida tradición medieval des-

de fechas muy tempranas ${ }^{48}$; por otro lado, algunos documentos inquisitoriales demuestran la amplia difusión de estas piezas en zonas como el Valle de México en una etapa bien avanzada del período colonial49; a su vez, numerosas representaciones actuales en muy diferentes estados del país atestiguan asimismo la pervivencia del tema, pero, aun en el caso de las dramatizaciones con una mayor tradición, resulta difícil remontar los textos dramáticos más allá de mediados del siglo $\mathrm{XIX}^{50}$. En definitiva, casi podríamos atrevernos a afirmar que lo que se ha mantenido

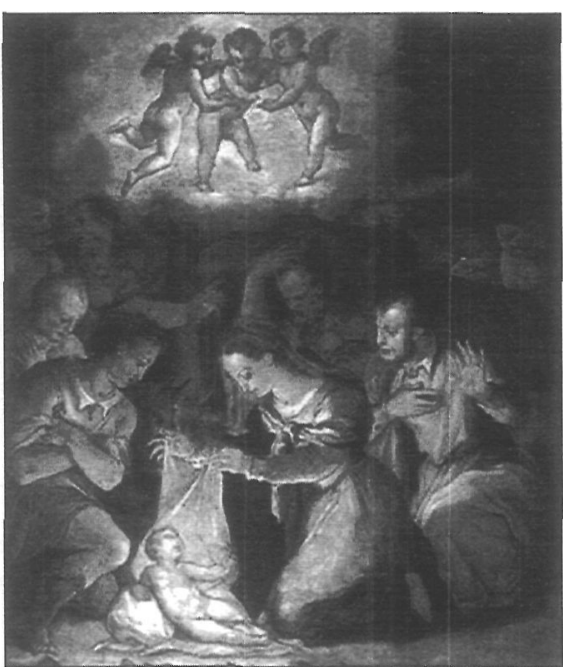

La adoración de los pastores. Giorgio Vasari. 1554 ca. Óleo sobre piedra. como tradición en México durante siglos (como en otros muchos países), más que una posible reelaboración de modelos ancestrales, ha sido la costumbre de representar las escenas de la Pasión de Cristo durante la Semana Santa siguiendo el esquema argumental de los Evangelios, que han constreñido siempre de forma necesaria los argumentos fueran o no la fuente directa de la obra

44

James Lockhart, Los nahuas después de la conquista. Historia social y cultural de la población indígena del México central, siglo XVI-XVIII, México, FCE, 1999, pág. 340.

45

Ibidem, pág. 342.

46

Sobre este problema en el ámbito español cf. Antonio Sánchez del Barrio, "Algunas noticias sobre el tiempo de Pasión Tradicional: El caso concreto de Medina del Campo», Revista de Folklore, 1987, tomo 7, núm. 83, pág. 169.

\section{7}

cf. Christian Duverger, La conversión de los indios de Nueva España, México, FCE, 1993, pág. 162 o Armando Partida, Teatro de evangelización en náhuatl, México, Consejo Nacional para la Cultura y las Artes, 1992, pág. 127.

48

Las Casas informó sobre representaciones de la Pasión que él mismo había presenciado: "Los misterios e historias de nuestra Redención es maravilla con cuánta perfección los hacen [los indios], y señaladamente les he notado muchas veces que en representar el descendimiento de la cruz y recibir el cuerpo del Salvador Nuestra Señora en su regazo, que llamamos la quinta angustia, tienen gracia especial») (Bartolomé de las Casas, Apologética historia de las Indias, Madrid, BAE, 1958, cap. 62, vol. 1, pág. 206); en la memoria del cacique don Toribio de Sandoval parece entreverse la representación anual de un neixcuitilli sobre la Pasión "Aquí comienza de cómo se hacía la pasión de Nuestro Dios; no era sólo como diversión; de cómo lo humillaron; para que nosotros recordemos cómo se hizo...; y para que recordemos cómo murió nuestro Dios, así se mandará hacer en su memoria» (cit. en Horcasitas, El teatro náhuatl, op. cit., pág. 336). Ya a fines del XVI, el franciscano fray Francisco de Gamboa organizaba representaciones de pasos de la Pasión en las que colaboraron fray Juan de Torquemada y fray Juan Bautista e incluso se consigna en la Séptima Relación de Chimalpahin la puesta en escena de La Pasión de Nuestro Señor Jesu- cristo en el barrio mexicano de Coyoacán: «Año 4-caña. 1587 (...). Este mismo año por primero vez se hizo una representación de la pasión de Nuestro Señor Jesucristo en el Viernes Santo en Coyohuacan» (Francisco de San Antón Muñoz Chimalpahin, Relaciones originales de Chalco Amaquemecan, México, FCE, 1965, págs. 290-291).

\section{9}

Como el expediente inquisitorial sobre «las representaciones teatrales de la Pasión y muerte de Ntro. Redentor» que se ejecutaban cada año en la jurisdicción de Chalco (1768), en el que los miembros del Santo Oficio dieron su opinión sobre este tipo de representaciones e incluso se adjuntaron textos dramáticos concretos (véase "Las representaciones teatrales de la Pasión», Boletín del Archivo General de la Nación, 1934, tomo V, núm. 3, págs. 332-356; cf. Juan Leyva, ed., La Pasión de Ozumba. E teatro religioso tradicional en el siglo XVIII novohispano, México, UNAM, 2001).

50

Así, por ejemplo, la representación actual de la Pasión de Iztapalapa, una de las más famosas de México y con más de un siglo de antigüedad, se desarrolla de acuerdo a un texto que poco tiene que ver con los consignados en el siglo XVIII, ya que está basado en la novela romántica El mártir del Gólgota de Pérez Escrich.

Reflexiones para una historia de la teatralidad religiosa popular en México

BEATRIZ ARACIL VARÓN 


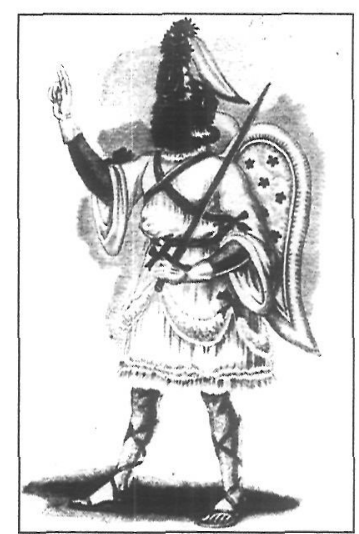

Indumentaria del ángel en la Pastorela de los siete vicios. Dibujo: Vicente T. Mendoza.

51

Pepe Rey, «Rasgos teatrales de la música de los cancioneros medievales", en Teatralidad medieval y su supervivencia, Alicante, Ajuntament d'Elx / Instituto de Cultura Juan Gil-Albert, 1998, pág. 92.

\section{2}

Véase Maximiano Trapero, La pastorada leonesa. Una pervi vencia del teatro medieval, Madrid, Sociedad Española de Musicología, 1982 (en especial págs. 106-111); opiniones contrarias al medievalismo de la pastorada las encontramos en autores como Ángel Gómez Moreno (cf. «Teatro medieval», en Carlos Alvar et al. La prosa y el teatro en la Edad Media, Madrid, Taurus, 1991, pág. 193).

53

Véase Carta de fray Pedro de Gante al rey don Felipe II. San Francisco de México, 1558, en Joaquín García leazbalceta, Nueva Colección de documentos para la historia de México, México, Salvador Chávez Hayhoe, 1941, II, págs. 206-207.

54

Véase Carta anua jesuita de 1596, en Mariano Cuevas, Historia de la Iglesia en México, 5 vols., México, Editorial Patria, 1946, II, pág. 413.

\section{5}

La obra de Juan de Cigorondo Égloga pastoril al nacimiento del niño Jesús, escrita en

Reflexiones para una historia de la teatralidad religiosa popular en México

BEATRIZ ARACIL VARÓN en cuestión (y precisamente por ello, como ya he apuntado, enmascaran en ocasiones las influencias de muy diverso tipo que reciben las representaciones).

Por lo que respecta al ciclo navideño, y más concretamente a las famosas pastorelas, la existencia, por un lado, de testimonios sobre representaciones con este tema a lo largo del período colonial y durante el siglo XIX y, por otro, la configuración actual de una estructura dramática bastante fija y diferenciada que puede ser rastreada en etapas anteriores permitiría aventurar algunas hipótesis sobre un proceso evolutivo bastante complejo.

En esencia, el origen de la pastorela (una tradición muy arraigada no sólo en México sino también en otros países latinoamericanos), como el de las pastoradas que aún hoy se representan en España (en especial en la región castellano-leonesa), se remonta a los inicios del teatro medieval peninsular; en concreto, al ciclo del Officium pastorum. Por lo que respecta a la península, Pepe Rey ha señalado cómo las primeras manifestaciones dramáticas pastoriles desembocaron hacia el siglo XV en tres formas diferentes: la pastorada, el auto y la ensalada, siendo la pastorada «la forma más tradicional»51. El hecho de que la estructura dramática de la actual pastorada leonesa, centrada en el anuncio del ángel y las siguientes disputas entre pastores (elementos básicos a los que se añaden otros como villancicos, presentaciones, ofrecimientos al Niño, despedidas...) no difiera del esquema habitual de los autos de Navidad de los siglos XV a XVII (que amplificaron a su vez el Officium pastorum) ha llevado a autores como Maximiano Trapero a defender que las pastoradas no nacieron como forma de popularización de un texto culto sino que, por el contrario, tienen un modelo anterior común a éstos y

\footnotetext{
el siglo XVI, fue publicada por primera vez en Othón Arróniz, Teatro de evangelización en Nueva España, México, UNAM, 1979, págs. 187-238; Cayetano Javier de Cabrera y Quintero escribió en el siglo XVIII un Coloquio al nacimiento de Nuestro Señor para ser representado en el Colegio de San Miguel de Bethlem de México que ha sido publicado en Joe Romero Salinas, La pastorela mexicana: origen y evolución SEP-Cultura/FONART, MéxiCo, 1984, págs. 129-141.
}

que, por tanto, podemos asegurar el origen medieval de las pastoradas actuales, que podrían considerarse como diversas variantes, tras el discurrir de siglos, de ese modelo medieval transmitido por tradición oral ${ }^{52}$.

De ser cierta la hipótesis de Trapero, la pastorela mexicana sería también una variante de ese modelo medieval, introducido en la Nueva España fundamentalmente en dos líneas paralelas: en primer lugar, como parte de las representaciones misioneras destinadas a la población indígena, según parecen apuntar testimonios como el del franciscano fray Pedro de Gante sobre los cantos escenificados en la Navidad de $1526^{53}$ o la descripción del coloquio pastoril representado en la misión jesuita de San Felipe (Sinaloa) en 1595 conservada en las Cartas Anuas de la Compañía ${ }^{54}$; en segundo lugar, incorporado al ámbito culto, tal como atestiguan los textos conservados de distintos autores a lo largo del período colonial, desde Juan Cigorondo hasta Cayetano Javier de Cabrera y Quintero ${ }^{55}$. Ambas tradiciones debieron convivir durante el período colonial e incluso recibir fuertes influencias mutuas en el siglo XIX, cuando autores teatrales como Fernández de Lizardi, Fernández Villa o Mariano Osorno se acercaron no al género culto pastoril sino a las formas populares de las pastorelas, que por entonces ya eran «endiabladas, llenas de impropiedades violentas, arrastradas en su falta de invención» ${ }^{56}$, para proponer una peculiar revitalización (y depuración) de éstas.

Es precisamente en el siglo XIX cuando encontramos las primeras piezas teatrales fijadas textualmente en las que se muestran los elementos definidores del género actual: el diálogo jocoso de los pastores en el que se citan ya las profecías en torno al nacimiento de Cristo, la intervención del Demonio para tentarlos, la llegada del ángel (san Miguel) para enfrentarse a Luzbel y vencerlo, la anunciación y la adoración ante el pesebre con cantos y danzas. Contamos, sin embargo, con testimonios que demuestran que el paso a este tipo de estructura dramática no fue ni mucho menos lineal: si, por un lado, se ha encontrado documentación que podría remontar su origen a la segunda mitad del siglo XVIII57, por otro, hay constancia manuscrita, todavía a comienzos del siglo XX, de pastorelas que, alejadas de esa estructura popularizada en el siglo XIX, mantenían vigentes elementos destinados a reforzar la fe e instruir en la doctrina cristiana a las comunidades indí- 
genas muy similares a los que debieron emplearse en el primer siglo de la colonia ${ }^{58}$.

En cuanto a las muy diversas danzas de «moros y cristianos» que se realizan en México, sobre las que continúa siendo imprescindible el ya citado trabajo de Arturo Warman, tal vez resulte más sencillo que en las formas anteriores -al menos en algunos casos- establecer el modo en que se han ido transformando desde su introducción en el territorio, siempre y cuando se trabajen las distintas variantes en sí mismas y en relación con el resto. Pondré solamente un ejemplo: entre los textos de representaciones religiosas tradicionales que logró reunir en la región de Chilapa (Guerrero) a fines de los 80, Ariza Acevedo incluye el de una danza de Los Moros Santiagos en la que, junto a Santiago y el Rey Moro, aparecen Vespasiano y Poncio Pilatos, aspecto sobre el cual comenta este investigador:

...esta versión de los Moros Santiagos desarrolla una historia más que basada en la fantasía, basada en la ingenuidad, en lo intemporal. En ella conviven personajes de distintas épocas, por ejemplo en la escuadra mora aparece Pilatos, un personaje real y contemporáneo de Cristo, de hace veinte siglos, lidiando con Santiago, un mito de la reconquista española que debió hacer su aparición por lo menos mil años después de Pilatos. Esto nos da una idea de que la intención del anónimo juglar de esta pieza, no fue la de contar un testimonio histórico, sino el interés de propagar la fe cristiana, de una manera entretenida, sin complicaciones, ni de fechas ni de nacionalidades ${ }^{59}$.

Sin negar la evidente finalidad catequizadora de la pieza, lo cierto es que la aparente incongruencia argumental de esta danza no se debe a la ingenuidad del supuesto autor, como propone Ariza ${ }^{60}$, sino al origen colonial de la representación: como ha señalado Weckmann,

Desde un principio, en la Nueva España el apóstol Santiago encabeza siempre a los cristianos, y Poncio Pilato frecuentemente a los indios. Esta interesante circunstancia revela la antigua relación de la danza de moros y cristianos con los temas tradicionales de los cantares de gesta, especialmente los relativos a la conquista de Jerusalén o a su destrucción a manos de Tito y Vespasiano ${ }^{61}$.

En efecto, desde fechas muy tempranas del período virreinal, debió operarse una confluencia entre el tema español de la Reconquista, con la figura central del patrón Santiago, muy presente en la cultura de los vencedores (que

derivaría a su vez, entre la población autóctona, hacia formas más propiamente indígenas como las danzas de chichimecas), y el de La destrucción de Jerusalén, que tuvo una presencia destacada en la literatura y el teatro medieval europeo ${ }^{62}$ y que se debió trasladarse asimismo a la Nueva España en el primer siglo de la colonia, como demuestra la pieza en náhuatl conservada sobre este tem $a^{63}$ (cuya escritura puede ser de fines del XVII o comienzos del XVIII, pero probablemente es copia de un pieza del XVI ${ }^{64}$ ). De hecho, el manuscrito mexicano de La destrucción de Jerusalén, a pesar de no incluir al apóstol Santiago como personaje, comienza con las siguientes palabras: "Aquí se asienta la vida del Señor Santiago, de cómo sucedió que destruyó a la gran ciudad de Jerusalén, a los judíos y a Pilatos» ${ }^{65}$, palabras que, más que un «engañoso título», como plantea Horcasitas, pueden ser reflejo de esa confluencia temática que venimos comentando y que en la representación de Chilapa se da ya de forma evidente.

Aunque todavía no estemos en condiciones de explicar las fases de dicha confluencia, parece lógico pensar que guarda a su vez relación con una temprana identificación, en el contexto novohispano, entre los judíos y los moros como enemigos de la verdadera $\mathrm{fe}^{66}$,

58

En un trabajo anterior expliqué ya cómo, por ejemplo, la Pastorela de viejos (para el año de 1912), hallada en Quinceo y transcrita por Adrián F. León, fue compuesta íntegramente en lengua indígena por un autor con suficientes conocimientos de doctrina cristiana (probablemente un sacerdote $\circ$ alguien muy cercano al entorno religioso) que aprovechó la representación teatral para transmitir a los fieles determinados conceptos doctrinales (véase Beatriz Aracil, "Pastorelas tradicionales indigenas en el siglo XIX", en ibidem, págs. 23-36, en especial págs. 25-30).

\section{9}

Ariza Acevedo, op. cit., pág. 347.

\section{0}

Quien olvida además que Santiago no es sólo un mito sino también, y ante todo, un personaje histórico, uno de los apóstoles de Cristo, contemporáneo de Poncio Pilatos.
61

Luis Weckmann, La herencia medieval de México, México, El Colegio de México-FCE, 1994, pág. 518.

\section{2}

Abordado en el mismo siglo I por Josefo en su De bello ludaico, este asunto tuvo una amplia difusión en la literatura medieval europea: del siglo XIII es el poema anónimo la Des truction de Jérusalem, escrito en lemosín, sobre el cual se hizo una versión inglesa y una francesa en prosa impresa en el siglo XV al menos siete veces y traducida al español a finales de ese mismo siglo (véase María Rosa Lida de Malkiel, Jerusalén: el tema literario de su cerco y destrucción por los romanos, Buenos Aires, Universidad de Buenos Aires, 1973) Por lo que respecta en concreto al ámbito teatral, Rouanet des tacó ya la importancia, entre otras obras sobre el tema, de La vengeance de Notre-Seigneur, obra impresa siete veces entre 1491 y 1539 (Léo Rouanet, ed., Colección de autos, farsas y coloquios del siglo XVI [1901], 4 vols., Hildesheim-Nueva York, Gerg Olms Verlag, 1979, IV, pág. $211)$; en España se conserva asimismo una pieza teatral, el Auto de la destrucción de Jerusalén, recogida en el Códice de Autos Viejos libidem, I, auto XXX, págs. 502-524), que pudo componerse a finales del XVI.

\section{3}

La obra fue publicada por primera vez por Francisco del Paso y Troncoso (Destrucción de Jerusalén. Auto en lengua mexicana (anónimo) escrito en letra del siglo XVII, Florencia, Tipografía de Salvador Landi, 1907) y más tarde por Horcasitas (El teatro náhuatl, op. cit., págs. 465-495).

64

Cf. la introducción de Paso y Troncoso lop. cit., págs. 134135 y Horcasitas, El teatro náhuatl, op. cit., pág. 461.

65 Ibidem, pág. 465.

66

Recordemos que esta identificación se da desde las primeras décadas de la evangelización, tal como se muestra en la puesta en escena de una deseada Conquista de Jerusalén (Tlaxcala, 1539), en la que, según fray Toribio Motolinía, los españoles y mexicanos se enfrentarían a «Moros y Judíos con mucha munición y bastimentos" (fray Toribio de Benavente Motolinía, Historia de los indios de la Nueva España, ed. de G. Baudot, Madrid, Castalia, 1985, pág. 206).

Reflexiones para una historia de la teatralidad religiosa popular en México

BEATRIZ ARACIL VARÓN 


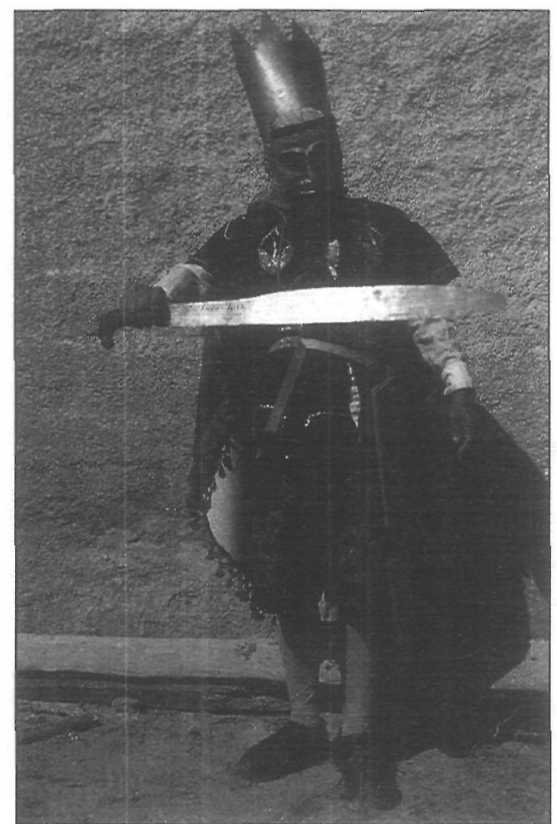

Mahoma de una danza de moros y cristianos en Oaxaca. Foto de Darina Robles.

\section{7}

Cf. a este respecto las "Tareas para una investigación futura» que propone Gisela Beutler en su artículo "Algunas observaciones sobre los textos de 'Moros y Cristianos' en México y Centroamérica», en A. David Kossoff et al. (eds.), Actas del VIII Congreso de la Asociación Internacional de Hispanistas, Madrid, Istmo, 1986, pág. 233.

\section{8}

Véase Warman, op. cit., págs. 14-16.

69

Id.

\section{0}

Annick Lempérière, «De la república corporativa a la nación moderna, México (18211869)", en Antonio Annino y François-Xavier Guerra, Inventando la nación, México, FCE, 2003, pág. 334

\section{1}

ld

72

Ibidem, pág. 330.

73

Véase ibidem, págs. 330-346.

74

Tavira, op. cit., pág. 21.

Reflexiones para una historia de la teatralidad religiosa popular en México

BEATRIZ ARACIL VARÓN así como con el hecho de que no sólo la estructura sino también el tema central de todas estas piezas sea el mismo: la conversión al cristianismo (con sus implicaciones políticas e ideológicas) desde distintas perspectivas (en Los Moros Santiagos, la conversión del gobernante, en la figura de Vespasiano, la del infiel derrotado por «España», que acepta a Cristo y recibe el bautismo, e incluso la negación de ésta, la ausencia de arrepentimiento).

Creo que el ejemplo citado sirve para demostrar cómo el cotejo de fuentes coloniales y contemporáneas es necesario para una correcta comprensión de ambas, como lo es también la utilización de los documentos externos o indirectos sobre el contexto cultural de dichas fuentes. Pero, al mismo tiempo, las preguntas que genera sobre las formas de popularización y de fusión de las variantes argumentales de una tradición muy diversa ponen de manifiesto lo lejos que estamos de una indagación sistemática y global en este sentido ${ }^{67}$; una indagación que, para cualquiera de las formas tradicionales, deberá tener en cuenta la premisa ya señalada por Warman de que la evolución social y cultural no tiende a la homogeneidad, sino «a la diversificación, al pluralismo", y que esa diversidad en México ha sido resultado sobre todo del contacto entre dos culturas, de un proceso de aculturación en el que los grupos indígenas, en su relación con la cultura dominante, han generado productos culturales influenciados por ésta, pero también voluntariamente divergentes, reafirmadores de la propia identidad 68 .

En el estudio de ese proceso evolutivo habrá que considerar además otra idea destacada por Warman: «las transformaciones básicas, las que cambian la orientación en la evolución de la culturas, no son el resultado de un proceso lento sino que por el contrario suceden en lapsos cortos y de gran intensidad» ${ }^{69}$. La tradición teatral religiosa se ha visto marcada en México, como el resto de elementos de la cultura, por momentos de transformación y ruptura como la Independencia o la Revolución. Apuntando sólo este tema (que deberá ser estudiado a fondo), parece que, al menos en el caso de la Independencia, este proceso implicó una quiebra pero también una recuperación de la tradición, y ello fue debido, por un lado, a que la indagación sobre la propia identidad surgida con los movimientos independentistas del siglo XIX llevó a una revitalización de manifestaciones propias de la tradición popular por parte de autores cultos (como hemos visto en el caso de la pastorela en manos de dramaturgos como Lizardi) y, por otro, a la propia situación de decadencia de la Iglesia católica en la segunda mitad del XIX. Como ha explicado Annick Lempérière, desde los inicios del nuevo gobierno, la religión católica, como «motivo de expresiones particularistas de identidad» vinculadas a santuarios o parroquias de santos patronos, se enfrentó a los deseos liberales de homogeneización de una identidad nacional ${ }^{70}$. Tras la Independencia, estas identidades particulares pervivieron porque

Cada ciudad, villa o pueblo conservaba su identidad propia no sólo gracias a su gobierno sino también mediante el culto a sus santos patronos y demás devociones particulares que llevaban a cabo cofradías y conventos, ayudados por el ayuntamiento ${ }^{71}$.

De hecho, esta situación fue apoyada en un principio por el poder: las constituciones mexicanas hasta 1847 incluyeron la religión católica como única del Estado y el calendario oficial mantuvo las «fiestas religiosas nacionales» (Semana Santa, Corpus Christi, Virgen de Guadalupe) junto a las nuevas fiestas «cívicas» ${ }^{72}$. Hubo que esperar a las Leyes de Reforma, y especialmente a la Ley Lerdo de 1856, con la desamortización de los bienes corporativos, y en concreto los eclesiásticos, para ver el triunfo de una república liberal que impuso una nueva forma de sociedad dominada definitivamente por el poder civil y no por el religioso ${ }^{73}$. Frente a un progreso urbano marcado por la festividad cívica, las comunidades rurales mantuvieron desde entonces sus fiestas religiosas como señas de identidad de una cultura marginal, sufriendo además un importante cambio al quedar libres de la autoridad del clero. El resultado fue una continuidad de las manifestaciones tradicionales respecto al período anterior, ya que, como explica Luis de Tavira, los laicos piadosos que se hicieron cargo de las ceremonias religiosas volvieron «a las tradiciones paralitúrgicas del pasado colonial» ${ }^{74}$, pero también una mayor libertad de las formas y, sobre todo, de los contenidos, que ya no debían ajustarse a la ortodoxia de la estructura eclesiástica (circunstancia muy reveladora para el estu- 
dio de algunas representaciones de la época, en especial de moros y cristianos, como ha demostrado Warman ${ }^{75}$ ).

$\mathrm{Al}$ estudio de estos contextos socio-políticos tan significativos habrá que añadir necesariamente el de los contextos propiamente culturales. En este sentido, se hace necesario profundizar en algunos aspectos poco trabajados como el de las influencias en el teatro religioso tradicional de otros géneros, tanto cultos como populares: así, por ejemplo, resulta imposible comprender el desarrollo de las representaciones de la Pasión a partir del último tercio del siglo XIX sin atender al éxito de la novela El Mártir del Gólgota (18631864), del escritor español Enrique Pérez Escrich ${ }^{76}$, o trazar la evolución de las danzas de moros y cristianos desde sus orígenes sin analizar sus conexiones con el Romancero. $Y$ es precisamente el vínculo con esa manifestación folklórica tan difundida en Hispanoamérica, destacado ya por investigadores como Beutler ${ }^{77}$, el que me lleva a plantear una última reflexión metodológica. Aludo para ello a un trabajo reciente de Milena Cáceres publicado en Lima, La fiesta de moros y cristianos en el Perú, en el que se estudia la Relación de la bistoria del Ave María del Rosario o Garcilazo que todavía se representa periódicamente en Huamantanga (departamento de Lima). El trabajo de Cáceres analiza esta danza de moros y cristianos cotejando su texto con distintas fuentes españolas de los siglos XVI y XVII sobre este episodio de la conquista de Granada, entre ellas, el romance «Cercado está Santa Fe», que para la autora constituye «el armazón sobre el que reposa» la pieza peruana $^{78}$. El libro puede servir de modelo para observar las posibilidades de estudios comparativos concretos en la dilucidación de estas vinculaciones entre la tradición teatral y la romancística, pero si lo cito además a este propósito es porque la autora maneja, en su análisis de la obra en cuestión, conceptos propuestos por Menéndez Pidal y Diego Catalán para el estudio del Romancero (concretamente los de «versión» y «motivo» ${ }^{79}$ ), esto es, traslada a la investigación teatral una metodología que ha resultado válida en el ámbito de la poesía tradicional.

A pesar de las evidentes diferencias entre ambos géneros, seguir los pasos de los estudios realizados durante más de un siglo sobre el Romancero en España y América puede abrir un vasto campo en las investigaciones sobre el teatro religioso tradicional. En primer lugar, porque, como hemos visto desde

el epígrafe anterior (y corrobora el trabajo de Cáceres), algunos conceptos planteados por los estudiosos del Romancero han resultado de gran funcionalidad para el estudio de ambas manifestaciones culturales tradicionales; en segundo lugar, porque los trabajos de conjunto realizados en este ámbito (entre los que destaca el de Mercedes Díaz Roig sobre el Romancero tradicional de América ${ }^{80}$ ) pueden servir de modelo para un necesario estudio comparativo con otras zonas geográficas del continente en las tres líneas temáticas propuestas (representaciones de la Pasión, pastorelas y danzas de moros y cristianos); en tercer lugar, porque los investigadores de la poesía tradicional han incorporado ya el teatro a sus perspectivas de análisis (como demuestran los títulos sobre este género que se incluyen en la Bibliografía descriptiva de la poesía tradicional y popular de México coordinada por Aurelio González ${ }^{81}$ ); y, por último, porque los estudios romancísticos cuentan incluso con algún proyecto de aplicación de las nuevas tecnologías (como el Proyecto del Romancero Pan-bispánico incorporado a la WEB por Suzanne Petersen ${ }^{82}$ ) que puede favorecer la sistematicidad a la hora de enfrentarnos a un objeto de estudio caracterizado precisamente por la multiplicidad de variantes.

La utilización de bases de datos informáticas, el manejo no sólo de las variantes teatrales sino también de la bibliografía crítica que sobre ellas se ha desarrollado en el resto de América Latina o los estudios comparativos entre géneros tradicionales pueden, junto al resto de los aspectos señalados a lo largo del presente epígrafe, ser base para futuras líneas de trabajo en el estudio histórico de las formas tradicionales de teatralidad religiosa en México. Advertía Menéndez Pidal en la nota preliminar a su Romancero hispánico:

Es verdad que el romancero de tan dilatada vida aparece dividido en dos porciones muy separadas: una antigua, perteneciente a los siglos XV y XVI, y otra moderna, correspondiente a los siglos XIX y XX. A primera vista parecerá incongruente establecer una relación efectiva entre ambas porciones (...). Y, sin

75

Véase Warman, op. cit., pág. 133. Las reflexiones de Warman podrían servir asimismo para comprender los heterodoxos finales de algunas danzas de moros y cristianos contemporáneas como la de Los Moros Chinos de Chilapa, que no incluye la conversión, pero sí el lamento de los moros derrotados por Santiago /cf. ed. de Ariza Acevedo, op. cit., póg. 419).
76

Base de La Pasión de lztapalapa, pero también de otras muchas representaciones actuales como las Judeas nicaragüenses (véase el trabajo de Roberto Sánchez Ramírez para el diario La Prensa, 21-3-2005, en http:// www-ni.laprensa, com. ni/archivo/2005/marzo/21/nacionales/nacionales-20050321. 01.html).

\section{7}

Véase Gisela Beutler, La historia de Fernando y Alamar. Contribución al estudio de las danzas de moros y cristianos en Puebla (México), Stuttgart, Franz Steiner Verlag Wiesbaden, 1984

\section{8}

Milena Cáceres Valderrama La fiesta de moros y cristionos, Lima, Pontificia Universidad Católica del Perú, 2005.

79

Conceptos que son consecuencia, a su vez, del de tradicionalidad ya planteado (véase ibidem, págs. 53-65).

\section{0}

Mercedes Díaz Roig, Romancero tradicional de América, México, El Colegio de México, 1990.

81

Aurelio González (coord.), Bibliografia descriptiva de la poesía tradicional y popular de México, México, El Colegio de México, 1993

\section{2}

Como explica la propia Petersen en su página (http://depts. washington.edu/hisprom/es panol/1, este proyecto a largo plazo pretende poner en línea «a) una bibliografía critica del género, b) una muestra representativa de todos los romances documentados por el mundo desde el siglo $X V, c)$ representación cartográfica de datos romancísticos primarios $y$ secundarios y d) reproducciones musicales de recitaciones originales y su notación musical»; cf. Suzanne Petersen, «El encuentro del Romancero en América con el proyecto romancístico en la WEB: asignatura pendiente», Anales de Literatura Hispanoamericana, 2001, núm. 30, págs. 135155.
Reflexiones para una historia de la teatralidad religiosa popular en México

BEATRIZ ARACIL VARÓN 
83

Menéndez Pidal, op. cit., págs. XIII-XIV.
Reflexiones para una historia de la teatralidad religiosa popular en México

BEATRIZ ARACIL VARÓN embargo, cuando examinemos el modo como ha ido descubriéndose el romancero actual, nos convenceremos de que él existió durante varios siglos antes, aunque ignorado o negado, y cuando penetremos el carácter y el valor de la producción antigua y de la moderna en su conjunto, veremos que no hay abismo ninguno ni solución de continuidad entre los romances de antes y los de dos siglos después ${ }^{83}$.

Sin duda un estudio sistemático, global y contextualizado, al que están contribuyendo ya los investigadores actuales, permitirá a la historiografía teatral en México (y en otras zonas de América) establecer no sólo, de manera semejante a la propuesta por $\mathrm{Me}$ néndez Pidal respecto a la poesía tradicional española e hispanoamericana, una «relación efectiva» entre el teatro evangelizador del siglo XVI y determinadas formas de teatralidad actuales sino también las claves de continuidad, ruptura, renovación y apropiación en el proceso evolutivo de las que son todavía hoy valiosas manifestaciones de la cultura mexicana.

\section{BIBLIOGRAFÍA}

Acuña, René, El teatro popular en Hispanoamérica. Una bibliografía anotada, México, UNAM, 1979.

Adame, Domingo, Teatros y teatralidades en México. Siglo XX, Xalapa, Universidad Veracruzana, 2004.

Alvar, Carlos et al., La prosa y el teatro en la Edad Media, Madrid, Taurus, 1991.

Annino, Antonio y François-Xavier Guerra (Coords.), Inventando la nación, México, FCE.

Aracil, Beatriz, El teatro evangelizador. Sociedad, cultura e ideología en la Nueva España del siglo XVI, Roma, Bulzoni, 1999.

- ; García, Óscar Armando; Ortiz, Alejandro; Raffi-Béraud, Catherine y Román Calvo, Norma (coords.), Fiesta y teatralidad de la pastorela mexicana, México, UNAM, 2004.

Ariza Acevedo, Maclovio, El teatro de evangelización en Chilapa, Guerrero, Chilpancingo, Universidad Autónoma de Guerrero, 1990.

Arrom, José Juan, El teatro de Hispanoamérica en la época colonial, La Habana, Anuario Bibliográfico Cubano, 1956.

Arróniz, Othón, Teatro de evangelización en Nueva España, México, UNAM, 1979.

Benavente Motolinía, fray Toribio de, Historia de los indios de la Nueva España, ed. de G. Baudot, Madrid, Castalia, 1985.
Beutler, Gisela, La bistoria de Fernando y Alamar. Contribución al estudio de las danzas de moros y cristianos en Puebla (México), Stuttgart, Franz Steiner Verlag Wiesbaden, 1984.

- , «Algunas observaciones sobre los textos de 'Moros y Cristianos' en México y Centroamérica», en A. David Kossoff et al. (eds.), Actas del VIII Congreso de la Asociación Internacional de Hispanistas, Madrid, Istmo, 1986, págs. 221-233.

Boal, Augusto, Técnicas latinoamericanas de teatro popular: una revolución copernicana al revés, Buenos Aires, Corregidor, 1975.

Cáceres Valderrama, Milena, La fiesta de moros y cristianos, Lima, Pontificia Universidad Católica del Perú, 2005.

Carvalho-Neto, Paulo de, "Concepto y realidad del teatro folklórico latinoamericano», Folklore Americano (México), 1977, núm. 23 (junio), págs. 101-115.

Casas, Bartolomé de las, Apologética bistoria de las Indias, Madrid, BAE, 1958.

Chimalpahin Cuauhtlehuanitzin, Francisco de San Antón Muñoz, Relaciones originales de Cbalco Amaquemecan, México, FCE, 1965.

Cuevas, Mariano, Historia de la Iglesia en México, 5 vols., México, Editorial Patria, 1946.

De Marinis, Marco, Comprender el teatro: lineamientos de una nueva teatrología, Buenos Aires, Galerna, 1997.

Destrucción de Jerusalén. Auto en lengua mexicana (anónimo) escrito en letra del siglo XVII, ed. de Francisco del Paso y Troncoso, Florencia, Tipografía de Salvador Landi, 1907.

Díaz Roig, Mercedes, Romancero tradicional de América, México, El Colegio de México, 1990.

Duverger, Christian, La conversión de los indios de Nueva España, México, FCE, 1993.

Frischmann, Donald, El nuevo teatro popular en México, México, INBA, 1990.

García Icazbalceta, Joaquín, Nueva Colección de documentos para la historia de México, 2 vols., México, Salvador Chávez Hayhoe, 1941.

González, Aurelio (coord.), Bibliografía descriptiva de la poesía tradicional y popular de México, México, El Colegio de México, 1993.

Horcasitas, Fernando, El teatro nábuatl, México, UNAM, 1974. 
- , Teatro nábuatl II, coord. por María Sten y Germán Viveros, México, UNAM, 2004.

Leyva, Juan (ed.), La Pasión de Ozumba. El teatro religioso tradicional en el siglo XVIII novohispano, México, UNAM, 2001.

Lida de Malkiel, María Rosa, Jerusalén: el tema literario de su cerco y destrucción por los romanos, Buenos Aires, Universidad de Buenos Aires, 1973.

Lockhart, James, Los nabuas después de la conquista. Historia social y cultural de la población indígena del México central, siglo XVI-XVIII, México, FCE, 1999.

Mendoza, Vicente T., «La Danza de la Conquista", Anuario de la Sociedad Folklórica de México, 1944, vol. IV, págs. 155-186.

- "Drama de la Pasión como se representa en Milpa Alta D.F. Manuscrito de Adalberto Fuentes Cruz», Anuario de la Sociedad Folklórica de México, 1949, vol. VI, págs. 249-371.

- Una Adoración de Pastores en Chilpancingo, México, UNAM, 1950.

- y Virginia R.R. de Mendoza, Folklore de San Pedro Piedra Gorda, Zacatecas, México, Instituto Nacional de Bellas Artes, 1952.

- , «Drama tradicional. Morisma de Zacatecas que se representa el 24 de junio», Anuario de la Sociedad Folklórica de México, 1954, vol. VIII, págs. 141-162.

- Folklore de la región central de Puebla, México, Centro Nacional de Investigación, Documentación e Información $\mathrm{Mu}$ sical Carlos Chávez, 1991.

Menéndez Pidal, Ramón, Romancero bispánico (hispano-portugués, americano y sefardi), tomo I, Madrid, Espasa-Calpe, 1968.

Merino de Zela, Mildred (comp.), Ensayos sobre folklore peruano, Lima, Universidad Ricardo Palma, 1999.

Oleza, Joan, «Las transformaciones del fasto medieval», en Teatro y espectáculo en la Edad Media, Instituto de Cultura Juan Gil-Albert, Diputación de Alicante y Ajuntament d'Elx, 1992, págs. 47-51.

Partida, Armando, Teatro de evangelización en nábuatl, México, Consejo Nacional para la Cultura y las Artes, 1992.
Petersen, Suzanne, «El encuentro del Romancero en América con el proyecto romancístico en la WEB: asignatura pendiente», Anales de Literatura Hispanoamericana, 2001, núm. 30, págs. 135-155.

«Las representaciones teatrales de la Pasión», Boletín del Archivo General de la Nación, 1934, tomo V, núm. 3, págs. 332-356.

Rey, Pepe, «Rasgos teatrales de la música de los cancioneros medievales», en Teatralidad medieval y su supervivencia (Actas del Seminario celebrado con motivo del III Festival d'Elx de Teatre i Música Medieval), Alicante, Ajuntament d'Elx / Instituto de Cultura Juan Gil-Albert, 1998, págs. 89-95.

Romero Salinas, Joel, La pastorela mexicana: origen y evolución, SEP-Cultura/FONART, México, 1984.

Rouanet, Léo (ed.), Colección de autos, farsas $y$ coloquios del siglo XVI [1901], 4 vols., Hildesheim-Nueva York, Gerg Olms Verlag, 1979, IV.

Sánchez del Barrio, Antonio, «Algunas noticias sobre el tiempo de Pasión Tradicional: El caso concreto de Medina del Campo», Revista de Folklore, 1987, tomo 7, núm. 83, págs. 169-175.

Tavira, Luis de (ed.), Autos, pastorelas y dramas religiosos. 1817-1862, México, Consejo Nacional para la Cultura y las Artes, 1995.

Toor, Frances, A treasure of Mexican Folkways, New York, Crown Publishers, 1947.

Trapero, Maximiano, La pastorada leonesa. Una pervivencia del teatro medieval, $\mathrm{Ma}$ drid, Sociedad Española de Musicología, 1982.

Villegas, Juan, Para un modelo de bistoria del teatro, Irvine (California), Gestos, 1997.

- Historia multicultural del teatro y las teatralidades en América Latina, Buenos Aires, Galerna, 2005.

Warman, Arturo, La danza de moros y cristianos, México, SEP-Setentas, 1972.

Weckmann, Luis, La herencia medieval de México, México, El Colegio de MéxicoFCE, 1994. en México 